\title{
Klinefelter syndrome and medical treatment: hypogonadism and beyond
}

\author{
Simon Chang, ${ }^{1,2}$ Anne Skakkebæk, ${ }^{2,3}$ Claus Højbjerg Gravholt ${ }^{2,4}$
}

\begin{abstract}
${ }^{1}$ Department of Clinical Biochemistry, Hospital of South West Denmark, and Unit for Thrombosis Research, Institute of Public Health, University of Southern Denmark, Esbjerg; ${ }^{2}$ Department of Endocrinology and Internal Medicine, Aarhus University Hospital, Aarhus; ${ }^{3}$ Department of Clinical Genetics, Aarhus University Hospital, Aarhus; ${ }^{4}$ Department of Molecular Medicine (MOMA), Aarhus University Hospital, Aarhus; Denmark
\end{abstract}

\begin{abstract}
Klinefelter syndrome (KS), though described more than 70 years ago, still imposes significant diagnostic challenges. Based on data from epidemiological studies, KS is associated with increased morbidity and mortality. Although the pathophysiology and etiology behind these observations are as yet not well understood, a significant contribution of hypogonadism, central to the syndrome, is traditionally suspected. However, other unknown effects inherent to the syndrome also seem to modify the disease pattern. Herein we show that KS is under-diagnosed since only roughly $25 \%$ of patients are diagnosed and the mean age of diagnosis is during adult life. KS is associated with increased morbidity resulting in loss of 2-5 years in lifespan with increased mortality from different diseases and a poor socioeconomic profile. Small testes, hypergonadothrophic hypogonadism and cognitive impairment are usually found. The accompanying hypogonadism can lead to altered body composition and a risk of developing metabolic syndrome, type 2 diabetes and cardiovascular disease. Cancer risk is generally not different from that observed in the background population, although specific cancers like breast cancer and extragonadal germ cell tumors are seen more frequently in KS. The mainstay of medical treatment is testosterone replacement therapy to both attenuate acute and long-term consequences of hypogonadism and possibly prevent the frequent comorbidity. We believe that the diagnostic challenges should be tackled more efficiently, while there is also a pressing need to generate better evidence for timing and the proper dose of testosterone replacement. We advocate for a multidisciplinary setup with the inclusion of pediatricians, speech therapists, general practitioners, psychologists, infertility specialists, urologists and endocrinologists.
\end{abstract}

Key words: Body composition, Heart disease, Hypogonadism, Morbidity, Mortality, Testosterone, Type 2 diabetes

Address for correspondence:

Claus Gravholt, MD, Professor, PhD, DMSc., Department of Endocrinology and Internal Medicine (MEA), Aarhus University Hospital, 8000 Aarhus C, Denmark; Tel.: + 45 78462004; E-mail: ch.gravholt@dadlnet.dk

Received: 24-06-2015, Accepted: 09-09-2015

\section{BACKGROUND AND CONTEXT}

The discovery of Klinefelter syndrome (KS) was somewhat coincidental. In the early 1940's, Fuller Albright, one of the world's most highly regarded endocrinologists both of his time and today, was at 
the peak of his career having made several crucial discoveries, particularly within the field of calcium metabolism. ${ }^{1}$ Albright held weekly general endocrinology clinics every Saturday at Massachusetts General Hospital and it was during one of these clinics that a young doctor by the name of Harry F. Klinefelter approached him asking about a tall male patient with gynecomastia and very small testes. The patient, a young recruit, had been referred by the Boston Draft Board and, working together, Albright and Klinefelter were able to identify a further 8 males with the same condition. ${ }^{2}$ They published their findings in the 1942 paper entitled "Syndrome characterized by gynecomastia, aspermatogenesis without A-Leydigism and increased excretion of follicle-stimulating hormone."3 Albright had let Klinefelter put his name first on the publication and, consequently, the syndrome became known as KS, although Klinefelter himself always credited Albright with the discovery. ${ }^{2}$

Later, the presence of additional chromatin in Klinefelter males was discovered ${ }^{4,5}$ and ultimately in 1959 the defining 47,XXY karyotype was described by Jacobs and Strong. ${ }^{6}$ Today, some 4000 scientific articles later, still much has yet to be described concerning KS. For instance, it is still not known exactly how the presence of an extra $\mathrm{X}$ chromosome causes the phenotype and morbidity pattern seen in KS, while in addition, issues concerning how to optimally treat the syndrome need to be further clarified.

In this context, it is also of particular interest that all the collected knowledge about $\mathrm{KS}$ is derived from diagnosed cases comprising only about $25 \%$ of the expected number of affected males. ${ }^{7,8}$ The fact that just a fraction of the expected cases of KS are ever diagnosed possibly underlines a central aspect of the syndrome, namely, that it is apparently possible to live what is considered a normal life, including having an education, a career, a love life and perhaps even a family, with KS without ever being diagnosed. The low diagnostic frequency is, of course, also worth considering when reviewing the scientific literature regarding KS, since looking only at the perhaps most clinically abnormal subset of patients potentially introduces bias. However, with this is mind, it seems that overall morbidity and mortality is increased in $\mathrm{KS},{ }^{9-11}$ while the syndrome is additionally associated with an array of socioeconomic challenges, ${ }^{12,13}$ including an increased criminal conviction rate. ${ }^{14}$ The aim of this review, besides presenting a general description of the syndrome, is to provide an overview of the most important comorbidities associated with KS and to specifically discuss how these are related to key hormonal aspects of the syndrome, namely, hypergonadotropic hypogonadism and testosterone supplementation therapy.

\section{PREVALENCE}

$\mathrm{KS}$ is the most common male sex chromosomal aneuploidy. The first estimate of the prevalence was based on six studies in newborns from the 1960's and 1970's finding the prevalence of XXY to be 1 in 1000 males, the same as for the XXX and XYY karyotypes (summarized by Hook and Hamerton). ${ }^{15}$ Danish registry studies have since described a prevalence of KS somewhere between 153 and 173 per 100,000 males, ${ }^{7,16}$ corresponding to approximately one in every 600 males being affected. Today, updated data show that the prevalence of KS is about 150 per 100,000 males and more frequent than $47, \mathrm{XXX}$ and $47, \mathrm{XYY}$ syndromes. Newer studies have also suggested that the prevalence may even be increasing and have proposed that the background could be an overall poorer sperm quality associated with increased hyperploidy of the sperm, with increased parental age possibly also being part of the explanation. ${ }^{17,18}$

Moreover, while not much is known about the influence of geography or ethnicity on the prevalence of KS, a recent Australian study found the prevalence of KS in Victoria, Australia, to be 223 per 100,000 males. ${ }^{19}$ The authors speculate that this relatively high prevalence might in part be due to a large proportion of Australian citizens being of Asian descent. This last hypothesis is based on the findings of another recent study describing a prevalence of KS among Asians of 355 per $100,000,{ }^{20}$ although, by contrast, a study on Klinefelter prevalence in Japan found a somewhat lower prevalence of KS at 60 per 100,000. ${ }^{21}$

In this context, it is important to underline that Klinefelter as such cannot be looked upon as a rare condition (which is normally defined by an incidence below 50 per 100,000 ) and that it is therefore reasonable to state that any physician or health professional will come in contact with the syndrome at some point, either knowingly or unknowingly. 


\section{DIAGNOSIS, PHENOTYPE AND GENETIC BACKGROUND}

Population-wide screening with routine karyotyping for detection of KS, Turner syndrome and other sex chromosome anomalies is not done in newborns anywhere in the world. Thus, diagnosis of KS is purely dependent on a qualified clinical suspicion based on often subtle clinical symptoms, with the most cardinal of findings being small firm testes. ${ }^{3}$ Otherwise, the syndrome is characterized by gynecomastia ${ }^{22}$ and above average height with long limbs and abdominal obesity, ${ }^{23}$ while it is important to emphasize that the phenotype often resembles that of normal men. Hence, using the current diagnostic practice only about $25 \%$ of expected cases are ever diagnosed and typically not until after late puberty. ${ }^{7}$ Whether it would be beneficial to introduce routine measures for early diagnosis has yet to be clarified. However, intuitively, an earlier diagnosis could give physicians better options for preventing comorbidities and, crucially, early identification of affected individuals could benefit the neurocognition and socioeconomic aspect of the syndrome. ${ }^{13}$ Thus, the need for pilot studies applying population-based genetic screening has been expressed to allow proper evaluation of the costs and benefits of such an approach in KS. ${ }^{24}$

The genetic background of KS is the presence of extra X chromosome(s), with $80 \%$ of affected individuals having the 47, XXY karyotype and the remaining cases presenting with either $47, \mathrm{XXY} / 46$ $\mathrm{XY}$ mosaicism or multiple $\mathrm{X}$ chromosome aneuploidy, often also with additional Y chromosomes. ${ }^{7,25}$ Fifty percent of cases are caused by maternal non-disjunction during the first or second meiotic divisions or even during mitosis in the developing zygote, while the other $50 \%$ of cases are caused by paternal nondisjunction during the first meiosis. ${ }^{25-27}$ The only identified risk for conception of a Klinefelter fetus is increasing maternal age due to increased meiotic non-disjunction. ${ }^{18}$ Although genetic markers related to the extra $\mathrm{X}$ chromosome have been investigated for a possible effect on the Klinefelter phenotype, so far no effect on the phenotype has been found related to the pattern of $\mathrm{X}$ chromosome inactivation ${ }^{23,28-30}$ or parental origin of the extra $\mathrm{X}$ chromosome. ${ }^{30,31}$ Nevertheless, one study found paternal origin to be associated with later onset of puberty ${ }^{32}$ and another observed a tendency towards an increased height to arm span ratio. ${ }^{23}$

A more convincing genetic marker modifying the Klinefelter phenotype, however, is the (CAG)n repeat length of the androgen receptor gene. It is believed that a high number of repeats are associated with a low androgen receptor sensitivity ${ }^{33}$ for circulating androgens, and it has been demonstrated in KS that (CAG)n repeat length is positively associated with height, height to arm span ratio, gynecomastia and small testes, ${ }^{34,35}$ as well as arm length, arm span and leg length. ${ }^{23}$

Other candidate genes responsible for the Klinefelter phenotype have been considered, especially the growth-related short stature homeobox gene (SHOX) situated on the $\mathrm{X}$ and $\mathrm{Y}$ chromosomes, since this gene is implicated not only in growth retardation in Turner syndrome but also in increased growth in syndromes with sex hormone aneuploidy via the so-called gene-dose effect. ${ }^{36}$ The reason is that this gene is not subjected to the usual $\mathrm{X}$ chromosome inactivation, which normally takes place in a female, but also to the supranumerary X chromosomes in KS. However, the vast majority of clinical characteristics present in $\mathrm{KS}$ are not explained by the SHOX gene and the other genetic mechanisms described above and we therefore lack a comprehensive understanding of the genotype-phenotype relation in KS. The current understanding of the $\mathrm{X}$ and $\mathrm{Y}$ chromosomes is based on evolutionary research: the sex chromosomes evolved from an identical pair of autosomes, whereas the $\mathrm{X}$ chromosome has retained most of the original genes (649 genes), the Y chromosomes has lost most and only 17 genes remain and are shared with the $\mathrm{X}$ chromosome. These mutual genes are involved in regulating other genes throughout the entire genome. ${ }^{37}$ Bellott et al recently showed that 12 of the remaining genes on the Y chromosome, having identical or near-identical haplotypes on the $\mathrm{X}$ chromosome, are needed in two copies and could therefore play a vital role in Turner syndrome. ${ }^{37}$ However, we hypothesize that these genes could also be involved in the phenotype of KS, where they are then present in 3 copies, and therefore expressed thrice, due to their status as escape genes and thus not subject to the usual inactivation of the extra $\mathrm{X}$ chromosome, which also takes place in $\mathrm{KS}$, as it does in the normal female. 
Klinefelter males are traditionally considered infertile ${ }^{38}$ but today some can achieve fatherhood by means of testicular sperm extraction and in vitro fertilization. ${ }^{18,39}$ This however has raised concerns about the heritability of the syndrome, especially after the finding of a small increase in the prevalence of KS in the offspring of Klinefelter fathers. ${ }^{40}$ Nevertheless, it is still too early to draw any firm conclusions on this matter. ${ }^{18}$

\section{HYPOGONADISM AND HORMONES}

The hormonal consequences of the Klinefelter karyotype is development of hypergonadotropic hypogonadism with decreased levels of androgens causing a feedback-mediated increased pituitary secretion of follicle stimulating hormone (FSH) and luteinizing hormone causing a relative increase in estrogen levels, resulting in an elevated estrogen to androgen ratio. ${ }^{3,25}$

The finding of an increased second to fourth finger ratio in $\mathrm{KS}$ gives indications that hypogonadism, so central to the syndrome, is already during fetal life affecting the fetus, giving rise to consequences measurable in adulthood. ${ }^{23,41}$ These findings correlate well with the degeneration of seminiferous tubules and hyperplasia of Leydig cells during fetal life, ${ }^{38}$ as well as the increased prevalence of microphallus and cryptorchidism seen in KS. ${ }^{42}$ The full effect of the apparent hypogonadal intrauterine milieu present in $\mathrm{KS}$ is not as yet understood but could very well also be exerting a negative influence, especially on neurocognition and "masculinization" of the brain. ${ }^{43,44}$

Normally in newborns, a postnatal endocrine surge with elevation of gonadotropins and sex hormones will set in shortly after birth. This "mini-puberty" and the resulting rise in testosterone in male infants are believed to be crucial for growth of male external genitalia and sperm production and may even affect sexual motivation..$^{43}$ Studies in KS infants have found the postnatal endocrine surge either to be attenuated with low testosterone levels ${ }^{45,46}$ or to present normal testosterone levels..$^{47,48}$ It is seems, however, that the "mini-puberty" in KS does follow a male pattern, with FSH levels peaking at 2-3 months of age, followed by a subsequent rapid decline ${ }^{48}$ and not as in females remaining at an elevated plateau for some years. ${ }^{43}$

As such, hypogonadism is not particularly clini- cally evident in KS until the beginning of puberty, and the lack of hypogonadism-related symptoms during childhood is also one of the reasons for the often significant diagnostic delay. The onset of puberty in KS occurs at the same time as in normal boys ${ }^{49}$ with some enlargement of the testes. ${ }^{25}$ However, starting in midpuberty the testes shrink again and the androgen levels remain low in spite of increasing LH and $\mathrm{FSH},{ }^{50}$ with the gonadotropins ultimately reaching the hypergonadotropic levels seen in adult KS. ${ }^{38}$ The resulting hypergonadotropic hypogonadism seen in adult KS is, on the other hand, varied and somewhat relative to testosterone levels typically in the subnormal or low normal range. ${ }^{25,51}$ Estrogen levels are raised early during puberty and remain slightly elevated in comparison with controls, ${ }^{50,52}$ but can also be normal.

\section{TESTOSTERONE TREATMENT}

Long-term male hypogonadism comprises a significant health risk by introducing a vicious circle of insulin resistance and obesity further worsening the hypogonadism and, along the way, leading to comorbidities, including loss of muscle and bone mass, the metabolic syndrome and type 2 diabetes which again entails further comorbidity as, for instance, heightened blood pressure and cardiovascular disease but also a markedly decreased quality of life. ${ }^{53}$ Thus, in most cases of KS testosterone treatment is recommended according to current guidelines on androgen deficiency ${ }^{54}$ to prevent this vicious circle from either occurring or running out of control. ${ }^{53,55,56}$ Testosterone treatment in non-Klinefelter hypogonadal males has been used for more than 70 years and has proved beneficial regarding obesity, blood pressure, glycemic control, bone mineral density, muscle mass and overall mortality as well as quality of life. ${ }^{54,57}$ Although studies on the effect of testosterone treatment in KS are few, the general consensus dictates that most men with KS should have testosterone treatment offered to them sometime around puberty with a target testosterone level in the high normal range. ${ }^{58}$ However, there are no large randomized placebo-controlled studies available to date to justify this assessment, and as a result the timing of initiation of testosterone treatment in KS still represents an area for further investigation, since indications of a possible benefit from testosterone treatment already during infancy have also been put 
forward. ${ }^{59,60}$ Specifically, new studies with treatment early in life have shown promising results in improving behavior ${ }^{60}$ and neurodevelopment ${ }^{61}$ and could thus have an overall positive effect on social integration.

Of note, from observational and nonrandomized studies some positive effects of testosterone treatment in KS have been documented, including improved libido, decreased fatigue, improved endurance and strength and also an overall improved mood with less irritability and better sleep. ${ }^{62,63}$ The impact of testosterone treatment in relation to specific disease entities is discussed separately below.

Current guidelines for testosterone treatment of hypogonadal men recommend against such therapy in men with breast or prostate cancer or symptomatic heart failure. ${ }^{54}$ As discussed below, KS seems to be associated with an increased risk for breast cancer and morbidity in general, but, to our knowledge, only one study has as yet directly aimed at investigating the safety of testosterone treatment in KS, while additionally considering other possible adverse effects including erythrocytosis, sleep apnea and also possibly aggressive behavior. In this retrospective evaluation of testosterone treatment in 110 Klinefelter no adverse events attributable to testosterone treatment were recorded. ${ }^{64}$ However, most of the study subjects also received aromatase inhibitor treatment and, furthermore, the subjects were all relatively young and followed up for only 5 years and, therefore, any cases of, for instance, breast cancer and other disease entities occurring later in life would not be expected.

\section{MEDICAL CONDITIONS ASSOCIATED WITH KLINEFELTER SYNDROME}

\section{Morbidity and mortality}

As already mentioned, hypogonadism is relevant to the etiology of many disease entities found with a higher than normal incidence in KS. ${ }^{9}$ However, overall morbidity and mortality in $\mathrm{KS}$ is increased for disease entities covering practically the entire ICD-10 range, and, hence, also for conditions not directly related to hypogonadism. ${ }^{65} \mathrm{KS}$ leads to more frequent hospitalization and a lifespan truncated by approximately 2.1 years. ${ }^{65}$ The background for this increased mortality is not thus far well understood and the question remains whether it is attributable to the syndrome itself or is mainly a consequence of increased morbidity and, specifically, living with low testosterone levels, since a recent review of testosterone and mortality finds low testosterone to be a biomarker for increased mortality in normal males. ${ }^{66}$ Below, separate disease entities relevant to $\mathrm{KS}$ are discussed in relation to incidence-, etiology- and disease-modifying effects of the hormonal profile characteristic of the syndrome.

\section{Cancer}

Based on epidemiological studies of morbidity and mortality, the overall cancer risk in KS is comparable to that of the general male population. ${ }^{9,67}$ By contrast, the distribution of individual malignant entities differs between Klinefelter males and normal males, with higher incidences of germ cell tumors and breast cancer and a lower incidence of prostate cancer in KS. ${ }^{6}$ Evidence for an association with other malignancies, especially leukemia and Non-Hodgkin lymphoma, has so far been equivocal. ${ }^{68}$ However, due to the rarity of KS in combination with the prevalence of individual malignant entities, the existing data should be regarded carefully.

\section{Extragonadal Germ Cell Tumors}

Extragonadal Germ Cell Tumors (GCT) are very rare and develop in the midline, most often located in the mediastinum. ${ }^{69,70}$ A markedly increased occurrence of GCT in KS has been demonstrated in both epidemiological and pathology based studies. ${ }^{68}$ The tumors are believed to be caused either by abnormal migration of germ cells during embryogenesis or to arise from primordial thymic cells or even be the result of reverse migration of carcinoma in situ cells from the gonads. ${ }^{70,71}$ In KS, GCTs have been found to be of primarily the non-seminomatous subtype and to debut at a younger age than in normal males. ${ }^{72}$ The background for this elevated incidence of GCTs in KS has not been studied, but it has been speculated that germ cell migration during fetal life is affected by changes in embryonic hormone exposure. ${ }^{68}$ Nonetheless, this is purely speculative as the etiology behind the condition as such is largely unknown with no apparent evidence so far linking either hypogonadism or testosterone treatment to an increased risk of developing GCT. It is of interest though that nonseminomatous GCTs are apparently associated with an 
increased occurrence of hematological malignancies, especially leukemia. ${ }^{73}$ The increased risk for GCTs in KS, however, does not compellingly translate to a concomitantly elevated risk for leukemia. ${ }^{74}$

\section{Breast Cancer}

Male breast cancer is rare with an incidence of approximately 1 per 100,000 and accounting for only $1 \%$ of all breast carcinomas, although the incidence, and notably in women, has been increasing in recent years. ${ }^{75,76}$ Observations suggesting that KS could represent an independent risk factor for male breast cancer were first published as early as $1955 .^{77}$ However, perhaps due to the rarity of breast cancer in KS, epidemiological studies of morbidity and mortality have either not been able to reproduce this association $^{9,78}$ or have found the risk to be elevated as much as 60 -fold compared with normal men. ${ }^{67} \mathrm{On}$ the other hand, meta-analyses of data concerning the incidence of male breast cancer from case reports and epidemiological data find the incidence of breast cancer in KS to be increased 4 to 30-fold compared with normal men. ${ }^{79,80}$ This makes KS the strongest independent risk factor for breast cancer in the male population. ${ }^{81}$ Mean age of onset of breast cancer in $\mathrm{KS}$ is 58 years of age ${ }^{82}$ with mean age at diagnosis among normal men being 67 years of age. ${ }^{75}$

There are, however, to date no studies specifically investigating etiology or presence of other risk factors in cases of breast cancer in KS, and possible explanations for the observed increased risk are thus based on experience from normal men and women. Nevertheless, several obvious conditions related to KS are worth considering in connection with breast cancer risk, and first and foremost the presence of hypergonadotropic hypogonadism that causes a skewed balance between estrogens and androgens. KS presents with relatively elevated levels of estrogens and there are abundant clinical data that high endogenous estrogen levels are associated with an increased risk for breast cancer in both premenopausal ${ }^{83}$ and postmenopausal women; ${ }^{84}$ likewise, administration of exogenous estrogens to males has been found to also increase the risk. ${ }^{85}$ The role of androgens in relation to breast cancer risk seems to be more complex, although a loss of testicular function, for instance caused by maldescensus, orchitis, testicular injury or orchiectomy, has been found to elevate the risk for breast cancer in males. ${ }^{80,86}$
On the other hand, high androgen levels in women have also been linked to an increased breast cancer risk. ${ }^{83,87}$ Moreover, a small study of 45 males on long-term administration of exogenous testosterone observed an increased risk for male breast cancer. ${ }^{88}$ In KS, exogenous testosterone could be linked to an increased risk for breast cancer via increasing conversion of testosterone into estrogen by aromatization. Also, as a consequence of hypogonadism, Klinefelter males tend to be obese ${ }^{23}$ with a high prevalence of the metabolic syndrome,${ }^{51}$ which again leads to increased aromatization of androgens ${ }^{89}$ potentially raising the risk for breast cancer. A possible association between the metabolic syndrome and breast cancer risk in women has recently been demonstrated..$^{90}$ In addition, interestingly, epidemiological data suggest that the incidence is highest for men with the 47,XXY/46,XY mosaic karyotype which again could speculatively be caused by differences in aromatization. ${ }^{67}$

Gynecomastia, present in approximately one third of Klinefelter males, does not seem to represent an independent risk factor for breast cancer in males ${ }^{91}$ but could be related to the risk as a pseudomarker of increased estrogen levels. ${ }^{92}$

Finally, it has also been proposed that the increased risk for breast cancer in KS can be attributed simply to the presence of an extra X chromosome, causing Klinefelter males, by some at present unknown mechanism, to inherit the same predisposition to this disease as seen in women. ${ }^{93}$

\section{Prostate Cancer}

The discovery of KS happened at more or less the same time as the discovery of an androgen dependency of prostate cancer, ${ }^{94}$ and today androgen deprivation therapy is a cornerstone in the treatment of this frequent malignancy in males. One could therefore assume that Klinefelter males would be protected from prostate cancer due to hypogonadism. Indeed, a lower than expected number of prostate cancer cases was registered in an epidemiological study of 696 Klinefelter males. ${ }^{78}$ Furthermore, a reduced incidence of and mortality from prostate cancer has been demonstrated ${ }^{95}$ also in a larger cohort. ${ }^{67}$ In addition, very few cases of prostate cancer in KS have been presented and only concomitantly with other malignancies,${ }^{77,96}$ or as representing extragonadal 
germ cell tumor, ${ }^{97}$ or in relation with testosterone treatment. ${ }^{98,99}$ However, the association between KS and prostate cancer appears to be complex. The largest analysis to date of data concerning the effect of endogenous sex hormones on prostate cancer risk comparing results from 18 prospective studies was not able to demonstrate any association between either androgens or estrogens and prostate cancer risk. ${ }^{100}$ On the other hand, obesity with an increased waisthip ratio and elevated insulin levels, associated with hypogonadism and $\mathrm{KS}$, has been found to increase the risk for prostate cancer. ${ }^{101,102}$

The association with testosterone treatment presented in two cases of prostate cancer in $\mathrm{KS}^{98,99}$ could be purely coincidental since most Klinefelter males are receiving this treatment. Meanwhile, evidence from randomized trials has not been able to establish any increased risk for prostate cancer attributable to testosterone treatment. ${ }^{103}$ However, no study has so far been adequately designed to fully elucidate this matter in normal males, let alone in KS.

Prostate specific antigen levels and prostate volume in both untreated and treated Klinefelter are well within the normal range, with prostate volume being slightly decreased compared with controls. ${ }^{104}$

\section{METABOLISM}

Central to the theory of a vicious circle leading to severe morbidity on the basis of hypogonadism in males is development of abdominal obesity followed by insulin resistance, ultimately causing diseases such as the metabolic syndrome and type 2 diabetes..$^{53}$ This series of events is well-described in normal males ${ }^{58}$ and abdominal obesity has consistently been found to be a characteristic trait in adult $\mathrm{KS}$, as shown in two recent studies. ${ }^{23,105}$ Furthermore, the epidemiological studies on morbidity and mortality have all found increased incidence of diabetes in KS, ${ }^{9,11,65}$ while the incidence of the metabolic syndrome is also observed to be not only increased but indeed associated with abdominal obesity and hypogonadism..$^{51,106}$ The question then remains whether the increased incidence of diabetes and the metabolic syndrome is further attenuated by the Klinefelter karyotype itself or whether it is merely an effect of hypogonadism and obesity. So far this question has not been adequately answered. However, when considering studies on obesity, it is important to note that the use of BMI to compare results from the normal male and the Klinefelter populations might not be appropiate due to an unfavorable muscle-tofat ratio in KS. It has been shown that for any given BMI, abdominal fat is increased in KS compared with controls $^{3,51}$ The build-up of abdominal fat and concomittant sarcopenia with loss of lean mass is, however, a feature of other types of male hypogonadism, ${ }^{58}$ but whether these changes are more pronounced in KS has not so far been investigated, although the finding of an increased body fat mass in KS even before puberty could support such a theory. ${ }^{107}$

In normal men presenting with abdominal obesity and hypogonadism, testosterone treatment has been found beneficial in reducing abdominal fat deposition and increasing lean mass and muscle strength. ${ }^{58}$ Further corroboration of an additional effect of the Klinefelter karyotype besides the effects of hypogonadism in upholding an unfavorable metabolic state could come from one study finding no change in BMI or weight in 19 Klinefelter males who, treated with testosterone injections for 48 weeks, reached normal testosterone levels. ${ }^{108}$ However, the relatively short follow-up in this study might not be sufficient to detect changes in fat deposition that build up over several years. By contrast, in cross-sectional studies, no effect on BMI, body fat mass or body fat percentage was observed comparing treated and untreated KS in adolescents, ${ }^{107}$ and in a study of 70 Klinefelter males of whom $50 \%$ were treated with testosterone, no effect was seen on BMI, waist circumference or weight, although body fat percentage and truncal fat percentage tended to be reduced in the treated group (P-value of 0.08 and 0.11 , respectively). ${ }^{51}$ Moreover, a recent study examining 132 Klinefelter males found no difference in weight, BMI or waist circumference between the treated and untreated groups ( $73 \%$ treated). ${ }^{105}$ Another recent study including 73 Klinefelter males also noted no difference in weight, BMI, waist circumference, abdominal fat mass, lean body mass or total fat mass comparing the treated $(68 \%)$ and the untreated group. In this study total body fat percentage and hip circumfernece was, however, reduced in treated versus untreated $\mathrm{KS}^{23}$

Thus, there is a need for longitudinal controlled studies with a standardized testosterone treatment and long follow-up to better distinguish the effects of the 
karyotype, hypogonadism and testosterone treatment on metabolism. Furthermore, the metabolic syndrome has been found to be approximately at 5 -fold higher incidence in KS compared with age-matched controls, with $46 \%$ of Klinefelter males fullfilling criteria for the metabolic syndrome. ${ }^{51}$ This reported incidence of the metabolic syndrome in KS seems also to be higher than in other populations of hypogonadal males, with one study finding the metabolic syndrome in $27 \%$ of unselected hypogonadal males ${ }^{109}$ and another study reporting an increased odds ratio of 2.3 for men with testosterone levels in the lowest quartile. ${ }^{110} \mathrm{In}$ addition, some gene dose effect of the $\mathrm{X}$ chromsome in Klinefelter is to be considered regarding the incidence of the metabolic syndrome. The overall incidence is comparable between men and women, although in certain ethnic populations incidence of the metabolic syndrome is increased as much as $50 \%$ in women, ${ }^{111}$ while newer data furthermore find that the overall prevalence is increasing, and, interestingly, especially in women. ${ }^{112}$

Overall, it seems likely that the metabolic consequences of KS are, to a large extent, driven by the resulting hypogonadism, but also that another and so far unknown effect is in play. Larger studies evaluating the effect of testosterone treatment on reversing the metabolic changes in KS and comparing KS populations with other populations of hypogonadal males and controls are required to gain further insight into this matter.

\section{CARDIOVASCULAR DISEASE}

Cardiovascular morbidity is central in $\mathrm{KS}$, being associated with an increased overall cardiovascular morbidity and mortality. ${ }^{9-11,65,95,113}$ Effects related to hypogonadism and the metabolic syndrome could shed some light on this association, though a good deal of information is still lacking. Cardiovascular malformations are common in another of the sex chromosome anomalies, Turner syndrome, ${ }^{114,115}$ and also in trisomy 13 (Patau's syndrome), 18 (Edwards syndrome) and 21 (Down's syndrome). ${ }^{116}$ Collected evidence of a high number of such malformations in KS has not been presented and is limited to only a few case reports. ${ }^{117,118}$ However, a markedly increased prevalence of mitral valve prolapse has been described, ${ }^{119,120}$ though it has not been confirmed in more recent studies. ${ }^{9}, 121,122$ Echocardiographic studies evaluating the function of the heart has consistently found impaired diastolic function in KS. ${ }^{121,122}$ In the study by Andersen et al, decreasing diastolic function was observed, along with decreasing free testosterone, also to be associated with increasing truncal fat and fasting plasma glucose levels. ${ }^{121}$ In the study by Pasquali et al, the diastolic dysfunction was seen to impair cardiopulmonary performance causing chronotropic incompetence, i.e. inability of the heart to increase its rate commensurate with increased activity or demand. ${ }^{122}$ In the study by Andersen et al, a significantly reduced mean left ventricular long axis function associated with increasing truncal fat and decreasing free testosterone was also demonstrated. These findings were most pronounced in individuals with the metabolic syndrome, with left ventricular function in Klinefelter males without the metabolic syndrome comparable to control subjects. ${ }^{121}$ In the study by Pasquali et al, left ventricular function evaluated by echocardiography was comparable to that of normal controls. ${ }^{122}$ Furthermore, in the study by Pasquali et al, the finding of chronotropic incompetence was consistent in both treated and non-treated KS, indicating that testosterone treatment did not normalize the condition, ${ }^{122}$ this however conflicting to some extent with the findings of an association between reduced heart function and reduced androgenicity in the study by Andersen et al. ${ }^{121}$ What is more, it has been established that diastolic dysfunction exhibits a strong association with atrial fibrillation, ${ }^{123}$ albeit no reliable data on the incidence of atrial fibrillation or other arrhythmias in KS are to date available.

A short QTc interval, evaluated by ECG, has been found in KS and moreover, further shortening of the QTc interval in testosterone treated individuals. ${ }^{124}$ Short QTc-syndrome is associated with cardiac arrhythmias and cardiac arrest, and, indeed, in the study the patient with the shortest QTc interval suffered cardiac arrest against the background of ventricular fibrillation. ${ }^{124}$ Furthermore, observations of increasing incidence of atrial fibrillation in aging males could partially be attributable to decreasing androgen levels ${ }^{125}$ and, in fact, a study found lower testosterone levels in males with isolated atrial fibrillation compared with controls. ${ }^{126}$ 
Overall, also considering obesity, diabetes and the metabolic syndrome being risk markers for atrial fibrillation, ${ }^{125}$ it seems reasonable to hypothesize an increased incidence of atrial fibrillation in KS. The fact that testosterone treatment could imply an increased risk for atrial fibrillation has been postulated on the basis of cases associated with anabolic steroid use but has yet to be properly investigated. ${ }^{125}$

Also importantly, KS patients exhibit an increased proneness to thrombosis. Compelling evidence for an increased frequency of venous thromboembolic disease in KS has been presented. Campbell and Price demonstrated an increased frequency of deep vein thrombosis (DVT) and pulmonary embolism (PE) compared with expected incidence rates in an observational study of 412 Klinefelter males. ${ }^{113}$ Swerdlow et al found a standardized mortality ratio (SMR) of 5.7 for $\mathrm{PE}$ and 7.9 for unspecified peripheral vascular disease in a British cohort of 3518 Klinefelter males, ${ }^{11}$ while Bojesen et al demonstrated a hazard ratio of 3.60 for PE and 6.63 for DVT in a cohort of 832 Klinefelter males in a registry study of hospital discharge diagnoses. ${ }^{9}$ Additionally, almost 30 case reports of severe venous thromboebolism (VTE), i.e. DVT and/ or PE in KS, have been presented. ${ }^{127-130}$ Furthermore, an up to 30-fold increase in the prevalence of leg ulcers is reported in $\mathrm{KS}^{131}$ with available evidence pointing to a connection between leg ulceration and a high risk for DVT. ${ }^{132}$

The risk for arterial thrombosis is also increased in KS, although the evidence is currently somewhat equivocal. In the British cohort, mortality was significantly increased from cerebrovascular disease (SMR 2.2 ), though on the other hand, significantly decreased from ischemic heart disease (SMR 0.7) ${ }^{11}$ In the Danish cohort, a hazard ratio of 2.15 for ischemic heart disease was observed for Klinefelter males compared with controls. ${ }^{9}$ Meanwhile, an insignificantly increased hazard ratio of $1.19(0.78-1.81)$ for cerebrovascular disease was seen.

The background for the thrombosis proneness in Klinefeleter syndrome is not thus far understood. In general, the etiology behind thrombotic disease is multifactorial and depends on a disturbance of the delicate haemostatic balance, as defined by Astrup. ${ }^{133,134}$ For VTE, the etiology is further characterized by
Virchow's triad of stasis, endothelial dysfunction and hypercoagulability. ${ }^{135}$ Several factors related to $\mathrm{KS}$ and the vicious circle of hypogonadism, as described above, could contribute to a disturbance of the hemostatic balance, thus increasing the risk for thrombosis. In particular, obesity, the metabolic syndrome and diabetes that are common in KS could raise the overall risk for thrombosis. ${ }^{136,137}$ Specifically, high BMI and low testosterone are associated with increased levels of the plasminogen activator inhibitor-1 (PAI-1) leading to defective fibrinolysis. ${ }^{138,139}$ Fibrinolysis in KS, however, has never been thoroughly investigated, even though one study demonstrated higher PAI-1 in 7 Klinefelter males with leg ulcerations compared to 6 Klinefelter males without leg ulcerations, ${ }^{140}$ and a recent study indeed demonstrated higher PAI-1 levels in KS compared with both male and female controls. ${ }^{105}$ However, PAI-1 was seen to be positively correlated to weight, ${ }^{141}$ for which the controls were not matched, while the higher PAI-1 observed in Klinefelter syndrome could simply be a pseudomarker for the also significantly increased weight. ${ }^{105}$ Interestingly however, the PAI-1 level was comparable between testosterone treated and untreated Klinefelter males, indicating that men with higher PAI-1 levels, and consequently defective fibrinolysis in Klinefelter, do not exhibit the same testosterone dependency as seen in normogonadic or even hypogonadotrophic hypogonadic men. ${ }^{105,138}$ What is more, the overall increased morbidity in Klinefelter is hypothesized to play a role due to the increased risk for thrombosis seen with inflammation as in inflammatory bowel disease ${ }^{142}$ and the incidence of infections as well as rheumatologic diseases which appear to be increased in KS. ${ }^{65}$

Arteriosclerosis is also important in the etiology of both VTE and cardiovascular disease. ${ }^{143}$ No large scale studies have to date investigated the incidence of arteriosclerosis in KS, but an increased intima media thickness of the carotids, associated with arteriosclerosis, has been demonstrated. ${ }^{122}$ Furthermore, other factors like dyslipidemia, also often present in $\mathrm{KS}$, could contribute to formation of arteriosclerotic plaques in KS. An independently arteriosclerosispromoting effect of low testosterone, though not clearly demonstrated, has been hypothesized on the basis of animal studies and population studies on cardiovascular death in males. ${ }^{66}$ 
In addition, the relatively high estrogen levels in KS could be of importance, since both high endogenous estrogen and administration of exogenous estrogen are associated with an increased risk for thrombosis. ${ }^{144,145}$ Correspondingly, increasing evidence for testosterone deficiency as a risk factor for cardiovascular disease has been proposed, ${ }^{57,146}$ although results from some major studies, perhaps most prominently The Framingham Heart Study, have not been able to demonstrate any association between sex hormone levels and cardiovascular disease. ${ }^{66,147}$ Conversely, recent studies have also indicated a possible contribution of testosterone treatment to the risk for both VTE ${ }^{148}$ and cardiovascular disease. ${ }^{149-152}$ The studies associating testosterone treatment with an increased risk for cardiovascular disease have, however, been profusely critized for flaws in design and statistical methods and it has been pointed out that beneficial effects of testosterone therapy have been demonstrated in relation to many traditional cardiovascular risk factors. ${ }^{57}$

Moreover, although the exact associations are not currently understood, a markedly reduced risk for cardiovascular disease is seen in women compared with men, ${ }^{153}$ and this gender effect could possibly play a role in sex hormone anuploidies.

Finally, based on case studies, a potential role of increased platelet aggregation associated with thrombosis in KS has been proposed. ${ }^{140,154,155}$ The likelihood of such an association is supported by increased platelet aggregation seen in type 2 diabetes ${ }^{156}$ and findings indicating that testosterone directly inhibits platelet aggregation by increasing nitric oxid release from the vascular endothelium. ${ }^{157}$ However, conversely, administration of testosterone to healthy males has also been found to increase platelet aggregation by increasing thromboxane A2 receptor density. ${ }^{158}$

\section{BONE DISEASE}

In women, a close tie exists between bone loss and estrogen deficiency, whether pre- or postmenopausal. ${ }^{159}$ Correspondingly, the same association between loss of bone mass and low estrogen levels has been demonstrated in men, mainly during puberty. ${ }^{160,161}$ The effect of testosterone on maintaining bone health is exerted both directly by binding to the androgen receptor expressed in bone cells, but also by conversion to estrogen by aromatization. ${ }^{161}$ Thus, low testosterone levels would predispose to development of ostepenia, and indeed several studies have confirmed this association. ${ }^{160,162}$ However, other studies have not been able to demonstrate any association between testosterone and bone mineral density (BMD). ${ }^{147}$ The question then is, what role does the hypogonadal setting play in $\mathrm{KS}$ in relation to bone health? The ultimate consequence of poor bone health is, inevitably, fractures, and epidemiological data have found an overall increased incidence of fractures, and especially osteoporotic fractures, as well as increased mortality associated with femur fractures in KS. ${ }^{9,11,65}$ Further, an 8-fold increase in incidence of osteoporosis is reported in KS compared with that in normal males. ${ }^{65}$ This again corresponds well with studies finding decreased BMD in several Klinefelter populations ${ }^{58,163}$ and indications of both reduced bone formation and increased bone resorption associated with the syndrome. ${ }^{164}$ However, that lowered testosterone levels should be a independent predictor for low BMD and osteoporosis in KS has yet to be established, as only associations between BMD and pseudomarkers, e.g. decreased muscle strength or $25 \mathrm{OH}$-vitmain $\mathrm{D}$, have so far been presented. ${ }^{165,166}$

Low levels of $25 \mathrm{OH}$-vitamin D are commonly found in male hypogonadism and are believed to be caused by insufficient expression of a vitamin $\mathrm{D}$ activating enzyme in the testes. A recent study of 127 Klinefelter males detected no association between lumbar or femoral BMD but demonstrated positive correlations for $25 \mathrm{OH}$-vitamin $\mathrm{D}$ and lumbar and femoral BMD. ${ }^{166}$ Furthermore, the study confirmed findings from other studies demonstrating a comparable incidence of low BMD in hypogonadal Klinefelter males compared with Klinefelter males with normal testosterone levels. ${ }^{167,168}$ Another study additionally demonstrated low $25 \mathrm{OH}$-vitamin $\mathrm{D}$ in 70 Klinefelter males compared with controls. ${ }^{169}$ In this study yet another possible marker of bone heath, insulin-like factor 3 (INSL3), was observed to be reduced in Klinefelter males who also had lowered BMD. However, no correlation between INSL3 and BMD was seen. ${ }^{169}$

Furthermore, no effect on BMD of the CAG repeat length polymorphism in the androgen receptor has so far been convincingly demonstrated in KS. ${ }^{34,167}$ Based 
on the knowledge that testosterone is particularly important for bone formation during puberty in males, it is then relevant to hypothesize that the reduced BMD observed in adult KS might not be strongly related to the adult testosterone level but rather conditioned by a relatively more severe testosterone deficiency in the critical years around puberty, and that these changes are never compensated for due to continued hypogonadism. This is supported by studies showing that testosterone treatment in adulthood does not seem to normalize BMD, ${ }^{166,170}$ while, on the other hand, one study determined that Klinefelter males treated with testosterone before the age of 20 are more likely to exhibit normal BMD than those treated later in life. ${ }^{171}$

In addition, one study found that treatment for 24 months with vitamin $\mathrm{D}(\mathrm{n}=8)$ was superior in improving BMD compared with testosterone treatment $(n=12)$ in Klinefelter males, ${ }^{166}$ although in this study the testosterone supplementation seems not to have been sufficient. However, the small number of treated patients in the groups inhibits generalization of the results and underlines the need for further studies in order to determine the optimal treatment regimen for not only preserving adult BMD but also securing sufficient bone formation during puberty. The role of estrogens should also be considered. Estradiol levels in $\mathrm{KS}$ are often higher than in normal males and further elevated by testosterone treatment, hence the balance between estrogen and androgen could be especially important in determining BMD in KS.

\section{IMMUNOLOGIAL DISEASES}

Normally, the incidences of autoimmune diseases are highest in women due to estrogens-mediated enhancement of the immune response while androgens act as suppressors. ${ }^{172}$ On that basis, an association between KS and susceptibility towards immunological disease could be hypothesized. However, so far epidemiological studies have not been able to clearly demonstrate an increased incidence of autoimmune disease in KS. Nevertheless, this could be due to lack of statistical power for the purpose of, for instance, establishing incidence of systemic lupus erythematosus (SLE) ${ }^{65}$ However, case reports of rheumatic disease in KS are plentiful, especially concerning SLE. ${ }^{173-175}$ Of note, one study found a more than 13-fold higher than expected prevalence of KS in a population of 213 men with SLE. ${ }^{175}$ Furthermore, justification for hypothesizing an increased incidence of autoimmune disease in $\mathrm{KS}$ is supported by evidence pointing to an association between the risk for such disease and a low androgen-to-estrogen ratio and a gene dose effect related to the $\mathrm{X}$ chromosome, ${ }^{176,177}$ both of which are important features of KS. On the other hand, it is also worth noting that inflamed tissue in itself is capable of increasing macrophagal conversion of testosterone to estradiol, this complicating understanding of hormonal cause and effect in autoimmune disease. ${ }^{173}$

The female-to-male incidence of SLE peaks at 9:1 in the reproductive years, ${ }^{176}$ while one study has found the calculated incidence rate of SLE in KS to be comparable to the incidence in women and decidedly higher than in normal males. ${ }^{175}$ The authors offer further evidence of an X chromosome gene dose effect by proposing the notion that SLE is virtually unreported in Turner syndrome. ${ }^{175}$ Furthermore, the presence of SLE-predisposing gene variants located on the X chromosome (IRAK1, MECCP2, TLR7) could give additional support for a gene dose effect. ${ }^{178}$

The association between endogenous sex hormones and development or severity of SLE is not thus far completely understood, although some studies have reported a higher incidence in women with higher estrogen levels. ${ }^{176}$ Also, an early menarche and use of estrogen-containing contraceptive agents or postmenopausal estrogen supplementation have been observed to as much as double the risk for SLE in women. ${ }^{179}$ Testosterone treatment has been found to reduce the severity of SLE in KS, ${ }^{180}$ while, in the same line of evidence, one small study has reported a high incidence of $\mathrm{KS}$ in a group of males presenting autoimmune disease and hypogonadism concomitantly. ${ }^{181}$ Lastly, total and free testosterone in males with rheumatic arthritis has been seen to be decreased, while testosterone treatment, on the other hand, decreased the severity of acute episodes of the disease. ${ }^{173}$

To our knowledge, only one study, looking specifically at the immunological features of KS, has observed higher levels of immunoglobulins, interleukins and certain clusters of differentiation of positive cells in untreated KS compared to matched controls; it 
furthermore demonstrated a reduction in these levels after 6 months of testosterone treatment. ${ }^{182}$

We have described lower free T4 levels in a large group of Klinefelter males in comparison with a matched control group, but with normal levels of TSH and free T3 levels and also normal thyroglobulin and thyroid peroxidase antibodies, and have suggested that these findings could be viewed as compensated hypothyroidism secondary to hypothalamic-pituitary dysfunction. ${ }^{183}$ In comparison with the situation in Turner syndrome, where about $50 \%$ of patients develop autoimmune hypothyroidism, ${ }^{184}$ it is striking that thyroid function largely seems to be normal in $\mathrm{KS}$ and not to pose a common clinical problem.

Overall, there appear to be indications of a possible connection between KS and susceptibility towards autoimmune disease; however, the evidence is still scant and interpretation of, for instance, epidemiological data should also incorporate the possible disease-modifying effects of testosterone treatment.

\section{PERSPECTIVE}

$\mathrm{KS}$, although not rare, is severely underdiagnosed, ${ }^{185}$ even though the consequences of being born with the 47,XXY karyotype are extensive, covering all aspects of life, from learning disabilities and poor social integration to infertility and increased morbidity with a reduced lifespan. We have, however, only recently begun to understand the deeper consequences inherent in the syndrome and key questions as yet remain unanswered. Firstly, the genetic mechanism driving the distinct phenotype is not at present fully understood. It seems obvious that the presence of an extra X chromosome must form the basis, but our understanding of how exactly this aneuploidy is capable of exerting such pervasive changes is lacking. Secondly, the optimal treatment regimen for ensuring the highest possible quality of life with KS has yet to be established. So far, treatment has mainly focused on replenishing testosterone deficiency by means of supplementation. However, high quality studies on the effect of this treatment in KS are few and central issues such as the target level for testosterone and the best timing for initiation of treatment are still to be elucidated. Epidemiological studies of morbidity and mortality in KS presented to date have, how- ever, not been able to separate treated and untreated males, while it will of course be of great interest to gain insight, also on the epidemiological scale, into the capability of long-term testosterone treatment to modify disease and mortality. Nonetheless, the scientific evidence seems more and more to support the claim that $\mathrm{KS}$ is more than just hypogonadism. It will thus be interesting to follow the continued quest for deeper understanding of cause and effect.

\section{REFERENCES}

1. Kleeman CR, Levine BS, Felsenfeld AJ, 2009 Fuller Albright: the consummate clinical investigator. Clin J Am Soc Nephrol 4: 1541-1546.

2. Loriaux DL, 2009 Harry F. Klinefelter: 1912-1990. Endocrinologist 1: 1-4.

3. Klinefelter HF, Reifenstein EC, Albright F, 1942 Syndrome characterized by gynecomastia, aspermatogenesis without A-Leydigism, and increased excretion of follicle-stimulating hormone. Jour Clin Endocrinol 2: 615-627.

4. Bradbury JT, Bunge RG, Boccabella RA, 1956 Chromatin test in Klinefelter's syndrome. J Clin Endocrinol Metab 16: 689.

5. Reis P JS, Mosbeck J, 1959 Letter to the Editor. Lancet 1: 962.

6. Jacobs PA, Strong JA, 1959 A case of human intersexuality having a possible XXY sex-determining mechanism. Nature 183: 302-303.

7. Bojesen A, Juul S, Gravholt CH, 2003 Prenatal and postnatal prevalence of Klinefelter syndrome: a national registry study. J Clin Endocrinol Metab 88: 622-626.

8. Groth KA, Skakkebaek A, Host C, Gravholt CH, Bojesen A, 2013 Clinical review: Klinefelter syndrome--a clinical update. J Clin Endocrinol Metab 98: 20-30.

9. Bojesen A, Juul S, Birkebaek NH, Gravholt CH, 2006 Morbidity in Klinefelter syndrome: a Danish register study based on hospital discharge diagnoses. J Clin Endocrinol Metab 91: 1254-1260.

10. Bojesen A, Juul S, Birkebaek N, Gravholt CH, 2004 Increased mortality in Klinefelter syndrome. J Clin Endocrinol Metab 89: 3830-3834.

11. Swerdlow AJ, Higgins CD, Schoemaker MJ, Wright AF, Jacobs PA, 2005 Mortality in patients with Klinefelter syndrome in Britain: a cohort study. J Clin Endocrinol Metab 90: 6516-6522.

12. Bojesen A, Stochholm K, Juul S, Gravholt CH, 2011 Socioeconomic trajectories affect mortality in Klinefelter syndrome. J Clin Endocrinol Metab 96: 2098-2104.

13. Skakkebaek A, Wallentin M, Gravholt CH, 2015 Neuropsychology and socioeconomic aspects of Klinefelter syndrome: new developments. Curr Opin Endocrinol Diabetes Obes 22: 209-216. 
14. Stochholm K, Bojesen A, Jensen AS, Juul S, Gravholt CH, 2012 Criminality in men with Klinefelter's syndrome and XYY syndrome: a cohort study. BMJ Open 2: e000650.

15. Hook E, Hamerton J, 1977 The frequency of chromosome abnormalities detected in consecutive newborn studies: differences between studies: results by sex and by severity of phenotypic involvement. In: Hook E, Porter H (eds) Population Cytogenetics: Studies in Humans, Academic Press, New York; pp 63-79.

16. Nielsen J, Wohlert M, 1990, Sex chromosome abnormalities found among 34,910 newborn children: results from a 13-year incidence study in Arhus, Denmark. Birth Defects Orig Artic Ser 26: 209-223.

17. Morris JK, Alberman E, Scott C, Jacobs P, 2008 Is the prevalence of Klinefelter syndrome increasing? Eur $\mathrm{J}$ Hum Genet 16: 163-170.

18. Tuttelmann F, Gromoll J, 2010 Novel genetic aspects of Klinefelter's syndrome. Mol Hum Reprod 16: 386395.

19. Herlihy AS, Halliday JL, Cock ML, McLachlan RI, 2011 The prevalence and diagnosis rates of Klinefelter syndrome: an Australian comparison. Med J Aust 194: 24-28.

20. Coffee B, Keith K, Albizua I, et al, 2009 Incidence of fragile X syndrome by newborn screening for methylated FMR1 DNA. Am J Hum Genet 85: 503-514.

21. Higurashi M, Iijima K, Ishikawa N, Hoshina H, Watanabe N, 1979 Incidence of major chromosome aberrations in 12,319 newborn infants in Tokyo. Hum Genet 46: 163-172.

22. Kamischke A, Baumgardt A, Horst J, Nieschlag E, 2003 Clinical and diagnostic features of patients with suspected Klinefelter syndrome. J Androl 24: 41-48.

23. Chang S, Skakkebaek A, Trolle C, et al, 2014 Anthropometry in Klinefelter syndrome - multifactorial influences due to CAG length, testosterone treatment and possibly intrauterine hypogonadism. J Clin Endocrinol Metab 100: E508-17.

24. Herlihy AS, McLachlan RI, 2015 Screening for Klinefelter syndrome. Curr Opin Endocrinol Diabetes Obes 22: 224-229.

25. Lanfranco F, Kamischke A, Zitzmann M, Nieschlag E, 2004 Klinefelter's syndrome. Lancet 364: 273-283.

26. Jacobs PA, Hassold TJ, Whittington E, et al, 1988 Klinefelter's syndrome: an analysis of the origin of the additional sex chromosome using molecular probes. Ann Hum Genet 52: 93-109.

27. Thomas NS, Hassold TJ, 2003 Aberrant recombination and the origin of Klinefelter syndrome. Hum Reprod Update 9: 309-317.

28. Iitsuka Y, Bock A, Nguyen DD, Samango-Sprouse CA, Simpson JL, Bischoff FZ, 2001 Evidence of skewed $\mathrm{X}$-chromosome inactivation in 47,XXY and 48,XXYY Klinefelter patients. Am J Med Genet 98: 25-31.

29. Ross NL, Wadekar R, Lopes A, et al, 2006 Methylation of two Homo sapiens-specific X-Y homologous genes in Klinefelter's syndrome (XXY). Am J Med Genet B Neuropsychiatr Genet 141b: 544-548.

30. Zinn AR, Ramos P, Elder FF, Kowal K, SamangoSprouse C, Ross JL, 2005 Androgen receptor CAGn repeat length influences phenotype of 47,XXY (Klinefelter) syndrome. J Clin Endocrinol Metab 90: 50415046.

31. Zeger MP, Zinn AR, Lahlou N, et al, 2008 Effect of ascertainment and genetic features on the phenotype of Klinefelter syndrome. J Pediatr 152: 716-722.

32. Wikstrom AM, Painter JN, Raivio T, Aittomaki K, Dunkel , 2006 Genetic features of the X chromosome affect pubertal development and testicular degeneration in adolescent boys with Klinefelter syndrome. Clin Endocrinol 65: 92-97.

33. Chamberlain NL, Driver ED, Miesfeld RL, 1994 The length and location of CAG trinucleotide repeats in the androgen receptor $\mathrm{N}$-terminal domain affect transactivation function. Nucleic Acids Res 22: 3181-3186.

34. Bojesen A, Hertz JM, Gravholt CH, 2011 Genotype and phenotype in Klinefelter syndrome - impact of androgen receptor polymorphism and skewed $\mathrm{X}$ inactivation. Int J Androl 34: e642-648.

35. Zitzmann M, Depenbusch M, Gromoll J, Nieschlag E, 2004 X-chromosome inactivation patterns and androgen receptor functionality influence phenotype and social characteristics as well as pharmacogenetics of testosterone therapy in Klinefelter patients. J Clin Endocrinol Metab 89: 6208-6217.

36. Ottesen AM, Aksglaede L, Garn I, et al, 2010 Increased number of sex chromosomes affects height in a nonlinear fashion: a study of 305 patients with sex chromosome aneuploidy. Am J Med Genet A 152a: 1206-1212.

37. Bellott DW, Hughes JF, Skaletsky H, et al, 2014 Mammalian Y chromosomes retain widely expressed dosagesensitive regulators. Nature 508: 494-499.

38. Aksglaede L, Wikstrom AM, Rajpert-De Meyts E, Dunkel L, Skakkebaek NE, Juul A, 2006 Natural history of seminiferous tubule degeneration in Klinefelter syndrome. Hum Reprod Update 12: 39-48.

39. Schiff JD, Palermo GD, Veeck LL, Goldstein M, Rosenwaks Z, Schlegel PN, 2005 Success of testicular sperm extraction and intracytoplasmic sperm injection in men with Klinefelter syndrome. J Clin Endocrinol Metab 90: 6263-6267.

40. Staessen C, Tournaye H, Van Assche E, et al, 2003 PGD in 47,XXY Klinefelter's syndrome patients. Hum Reprod Update 9: 319-330.

41. Manning JT, Kilduff LP, Trivers R, 2013 Digit ratio (2D:4D) in Klinefelter's syndrome. Andrology 1: 9499.

42. Fennoy I, 2011 Testosterone and the child (0-12 years) with Klinefelter syndrome (47XXY): a review. Acta Paediatr 100: 846-850.

43. Guatelli-Steinberg D, Boyce J, 2012 The Postnatal 
Endocrine Surge and Its Effects on Subsequent Sexual Growth. In: Preedy V (ed) Handbook of Growth and Growth Monitoring in Health and Disease. 1st ed, Springer-Verlag, New York; pp, 663-680.

44. Wilson JD, 2001 Androgens, androgen receptors, and male gender role behavior. Horm Behav 40: 358-366.

45. Lahlou N, Fennoy I, Carel JC, Roger M, 2004 Inhibin $\mathrm{B}$ and anti-Mullerian hormone, but not testosterone levels, are normal in infants with nonmosaic Klinefelter syndrome. J Clin Endocrinol Metab 89: 1864-1868.

46. Ross JL, Samango-Sprouse C, Lahlou N, Kowal K, Elder FF, Zinn A, 2005 Early androgen deficiency in infants and young boys with 47,XXY Klinefelter syndrome. Horm Res 64: 39-45.

47. Aksglaede L, Petersen JH, Main KM, Skakkebaek NE, Juul A, 2007 High normal testosterone levels in infants with non-mosaic Klinefelter's syndrome. Eur J Endocrinol 57: 345-350.

48. Cabrol S, Ross JL, Fennoy I, Bouvattier C, Roger M, Lahlou N, 2011 Assessment of Leydig and Sertoli cell functions in infants with nonmosaic Klinefelter syndrome: insulin-like peptide 3 levels are normal and positively correlated with LH levels. J Clin Endocrinol Metab 96: E746-753.

49. Christiansen P, Andersson AM, Skakkebaek NE, 2003 Longitudinal studies of inhibin B levels in boys and young adults with Klinefelter syndrome. J Clin Endocrinol Metab 88: 888-891.

50. Salbenblatt JA, Bender BG, Puck MH, Robinson A, Faiman C, Winter JS, 1985 Pituitary-gonadal function in Klinefelter syndrome before and during puberty. Pediatr Res 19: 82-86.

51. Bojesen A, Kristensen K, Birkebaek NH, et al, 2006 The metabolic syndrome is frequent in Klinefelter's syndrome and is associated with abdominal obesity and hypogonadism. Diabetes Care 29: 1591-1598.

52. Wikstrom AM, Dunkel L, 2008 Testicular function in Klinefelter syndrome. Horm Res 69: 317-326.

53. Bojesen A, Gravholt CH, 2007 Klinefelter syndrome in clinical practice. Nat Clin Pract Urol 4: 192-204.

54. Bhasin S, Cunningham GR, Hayes FJ, et al, 2010 Testosterone therapy in men with androgen deficiency syndromes: an Endocrine Society clinical practice guideline. J Clin Endocrinol Metab 95: 2536-2559.

55. Gravholt CH, Jensen AS, Host C, Bojesen A, 2011 Body composition, metabolic syndrome and type 2 diabetes in Klinefelter syndrome. Acta Paediatr 100: 871-877.

56. Radicioni AF, Ferlin A, Balercia G, et al, 2010 Consensus statement on diagnosis and clinical management of Klinefelter syndrome. J Endocrinol Invest 33: 839-850.

57. Morgentaler A, Miner MM, Caliber M, Guay AT, Khera M, Traish AM, 2015 Testosterone therapy and cardiovascular risk: advances and controversies. Mayo Clin Proc 90: 224-251.

58. Host C, Skakkebaek A, Groth KA, Bojesen A, 2014
The role of hypogonadism in Klinefelter syndrome. Asian J Androl 16: 185-191.

59. Simpson JL, de la Cruz F, Swerdloff RS, et al, 2003 Klinefelter syndrome: expanding the phenotype and identifying new research directions. Genet Med 5: 460-468.

60. Samango-Sprouse C, Stapleton EJ, Lawson P, et al, 2015 Positive effects of early androgen therapy on the behavioral phenotype of boys with 47,XXY. Am J Med Genet C Semin Med Genet 169:150-157.

61. Samango-Sprouse CA, Sadeghin T, Mitchell FL, et al, 2013 Positive effects of short course androgen therapy on the neurodevelopmental outcome in boys with 47,XXY syndrome at 36 and 72 months of age. Am J Med Genet A 161A: 501-508.

62. Nielsen J, Pelsen B, Sorensen K, 1988 Follow-up of 30 Klinefelter males treated with testosterone. Clin Genet 33: 262-269.

63. Meikle AW, Dobs AS, Arver S, Caramelli KE, Sanders SW, Mazer NA, 1998 Androgen replacement in the treatment of Klinefelter's syndrome: efficacy and safety of a nonscrotal permeation-enhanced testosterone transdermal system. Endocr Pract 4: 17-22.

64. Mehta A, Clearman T, Paduch DA, 2014 Safety and efficacy of testosterone replacement therapy in adolescents with Klinefelter syndrome. J Urol 191: Suppl 5: 1527-1531.

65. Bojesen A, Gravholt CH, 2011 Morbidity and mortality in Klinefelter syndrome (47,XXY). Acta Paediatr 100: 807-813.

66. Muraleedharan V, Jones TH, 2014 Testosterone and mortality. Clin Endocrinol 81: 477-487.

67. Swerdlow AJ, Schoemaker MJ, Higgins CD, Wright AF, Jacobs PA, 2005 Cancer incidence and mortality in men with Klinefelter syndrome: a cohort study. J Natl Cancer Inst 97: 1204-1210.

68. De Sanctis V, Fiscina B, Soliman A, Giovannini M, Yassin M, 2013 Klinefelter syndrome and cancer: from childhood to adulthood. Pediatr Endocrinol Rev 11: 44-50.

69. Kaatsch P, Hafner C, Calaminus G, Blettner M, Tulla M, 2015 Pediatric germ cell tumors from 1987 to 2011: incidence rates, time trends, and survival. Pediatrics 135: e136-143.

70. Volkl TM, Langer T, Aigner T, et al, 2006 Klinefelter syndrome and mediastinal germ cell tumors. Am J Med Genet A 140: 471-481.

71. Weidner N, 1999 Germ-cell tumors of the mediastinum. Semin Diagn Pathol 16: 42-50.

72. Nichols CR, Heerema NA, Palmer C, Loehrer PJ, Sr, Williams SD, Einhorn LH, 1987 Klinefelter's syndrome associated with mediastinal germ cell neoplasms. J Clin Oncol 5: 1290-1294.

73. Hartmann JT, Nichols CR, Droz JP, et al, 2000 Hematologic disorders associated with primary mediastinal nonseminomatous germ cell tumors. J Natl Cancer Inst 
92: 54-61.

74. Keung YK, Buss D, Chauvenet A, Pettenati M, 2002 Hematologic malignancies and Klinefelter syndrome. a chance association? Cancer Genet Cytogenet 139: 9-13.

75. Giordano SH, Cohen DS, Buzdar AU, Perkins G, Hortobagyi GN, 2004 Breast carcinoma in men: a population-based study. Cancer 101: 51-57.

76. White J, Kearins O, Dodwell D, Horgan K, Hanby AM, Speirs V, 2011 Male breast carcinoma: increased awareness needed. Breast Cancer Res 13: 219.

77. Bauer DD, Erickson RL, 1955 Male breast cancer; Klinefelter syndrome with prostatic, adrenal and mammary tumors. Northwest Med 54: 472-476.

78. Hasle H, Mellemgaard A, Nielsen J, Hansen J, 1995 Cancer incidence in men with Klinefelter syndrome. Br J Cancer 71: 416-420.

79. Brinton LA, 2011 Breast cancer risk among patients with Klinefelter syndrome. Acta Paediatr 100: 814-818.

80. Sasco AJ, Lowenfels AB, Pasker-de Jong P, 1993 Review article: epidemiology of male breast cancer. A meta-analysis of published case-control studies and discussion of selected aetiological factors. Int J Cancer 53: 538-549.

81. Gomez-Raposo C, Zambrana Tevar F, Sereno Moyano M, Lopez Gomez M, Casado E, 2010 Male breast cancer. Cancer Treat Rev 36: 451-457.

82. Evans DB, Crichlow RW, 1987 Carcinoma of the male breast and Klinefelter's syndrome: is there an association? CA Cancer J Clin 37: 246-251.

83. Eliassen AH, Missmer SA, Tworoger SS et al, Endogenous steroid hormone concentrations and risk of breast cancer among premenopausal women. J Natl Cancer Inst 4: 1406-15.

84. Key T, Appleby P, Barnes I, Reeves G, 2002 Endogenous sex hormones and breast cancer in postmenopausal women: reanalysis of nine prospective studies. J Natl Cancer Inst 94: 606-616.

85. Mc CJ, Higgins CC, 1951 Bilateral carcinoma of male breast after estrogen therapy. J Am Med Assoc 146: 7-9.

86. Thomas DB, Jimenez LM, McTiernan A, et al, 1992 Breast cancer in men: risk factors with hormonal implications. Am J Epidemiol 135: 734-748.

87. Missmer SA, Eliassen AH, Barbieri RL, Hankinson SE, 2004 Endogenous estrogen, androgen, and progesterone concentrations and breast cancer risk among postmenopausal women. J Natl Cancer Inst 96: 1856-1865.

88. Medras M, Filus A, Jozkow P, Winowski J, SicinskaWerner T, 2006 Breast cancer and long-term hormonal treatment of male hypogonadism. Breast Cancer Res Treat 96: 263-265.

89. Vandewalle S, De Schepper J, Kaufman JM, 2015 Androgens and obesity in male adolescents. Curr Opin Endocrinol Diabetes Obes 22: 230-237.

90. Bhandari R, Kelley GA, Hartley TA, Rockett IR, 2014 Metabolic syndrome is associated with increased breast cancer risk: a systematic review with meta-analysis. Int J Breast Cancer 2014: ID 189384.

91. Giordano SH, Buzdar AU, Hortobagyi GN, 2002 Breast cancer in men. Ann Intern Med 137: 678-687.

92. Pensler JM, Silverman BL, Sanghavi J, et al, 2000 Estrogen and progesterone receptors in gynecomastia. Plast Reconstr Surg 106: 1011-1013.

93. Lynch HT, Kaplan AR, Lynch JF, 1974 Klinefelter syndrome and cancer. A family study. JAMA 229: 809-811.

94. Huggins C, Hodges CV, 1941 Studies on prostatic cancer: I. The effect of castration, of estrogen and of androgen injection on serum phosphatases in metastatic carcinoma of the prostate. Cancer Res 1: 293-297.

95. Price WH, Clayton JF, Wilson J, Collyer S, De Mey R, 1985 Causes of death in X chromatin positive males (Klinefelter's syndrome). J Epidemiol Community Health 39: 330-336.

96. Pienkos EJ, Meisner LF, 1991 Adenocarcinoma of the prostate in a 41-year-old man with XXY karyotype and chronic lymphocytic leukemia: report of a case. J Urol 145: 148-150.

97. Namiki K, Tsuchiya A, Noda K, et al, 1999 Extragonadal germ cell tumor of the prostate associated with Klinefelter's syndrome. Int J Urol 6: 158-161.

98. Bydder SA, Joseph DJ, Weinstein S, Stuckey BG, 2007 Prostate cancer following testosterone replacement in Klinefelter syndrome. ANZ J Surg 77: 93-94.

99. Hwang JJ, Dharmawardana PG, Uchio EM, Wynberg J, Phillips JL, 2003 Prostate cancer in Klinefelter syndrome during hormonal replacement therapy. Urology 62: 941.

100. Roddam AW, Allen NE, Appleby P, Key TJ, 2008 Endogenous sex hormones and prostate cancer: a collaborative analysis of 18 prospective studies. J Natl Cancer Inst 100: 170-183.

101. Hsing AW, Chua S, Jr, Gao YT, et al, 2001 Prostate cancer risk and serum levels of insulin and leptin: a population-based study. J Natl Cancer Inst 93: 783789.

102. MacInnis RJ, English DR, 2006 Body size and composition and prostate cancer risk: systematic review and meta-regression analysis. Cancer Causes Control 17: 989-1003.

103. Fernandez-Balsells MM, Murad MH, Lane M, et al, 2010 Clinical review 1: Adverse effects of testosterone therapy in adult men: a systematic review and metaanalysis. J Clin Endocrinol Metab 95: 2560-2575.

104. Selice R, Caretta N, Di Mambro A, et al, 2013 Prostate volume and growth during testosterone replacement therapy is related to visceral obesity in Klinefelter syndrome. Eur J Endocrinol 169: 743-749.

105. Zitzmann M, Bongers R, Werler S, et al, 2015 Gene expression patterns in relation to the clinical phenotype in Klinefelter syndrome. J Clin Endocrinol Metab 100: E518-523. 
106. Ishikawa T, Yamaguchi K, Kondo Y, Takenaka A, Fujisawa M, 2008 Metabolic syndrome in men with Klinefelter's syndrome. Urology 71: 1109-1113.

107. Aksglaede L, Molgaard C, Skakkebaek NE, Juul A, 2008 Normal bone mineral content but unfavourable muscle/fat ratio in Klinefelter syndrome. Arch Dis Child 93: 30-34.

108. Jo DG, Lee HS, Joo YM, Seo JT, 2013 Effect of testosterone replacement therapy on bone mineral density in patients with Klinefelter syndrome. Yonsei Med J 54: 1331-1335.

109. Naifar M, Rekik N, Messedi M, et al, 2015 Male hypogonadism and metabolic syndrome. Andrologia 47: 579-586.

110. Laaksonen DE, Niskanen L, Punnonen K, et al, 2014 Testosterone and sex hormone-binding globulin predict the metabolic syndrome and diabetes in middle-aged men. Diabetes Care 27: 1036-1041.

111. Ford ES, Giles WH, Dietz WH, 2002 Prevalence of the metabolic syndrome among US adults: findings from the third National Health and Nutrition Examination Survey. JAMA 287: 356-359.

112. Ford ES, Giles WH, Mokdad AH, 2004 Increasing prevalence of the metabolic syndrome among u.s. Adults. Diabetes Care 27: 2444-2449.

113. Campbell WA, Price WH, 1981 Venous thromboembolic disease in Klinefelter's syndrome. Clin Genet 19: $275-280$.

114. Gravholt CH, Juul S, Naeraa RW, Hansen J, 1998 Morbidity in Turner syndrome. J Clin Epidemiol 51: 147-158.

115. Mortensen KH, Andersen NH, Gravholt CH, 2012 Cardiovascular phenotype in Turner syndrome--integrating cardiology, genetics, and endocrinology. Endocr Rev 33: 677-714.

116. Emanuel R, 1970 Genetics and congenital heart disease. Br Heart J 32: 281-291.

117. Agarwal S, Dekam MJ, 2011 Multiple cardiac anomalies in an elderly man with Klinefelter's syndrome. Singapore Med J 52: e15-17.

118. Rosenthal A, 1972 Cardiovascular malformations in Klinefelter's syndrome: report of three cases. J Pediatr 80: 471-473.

119. Fricke GR, Mattern HJ, Schweikert HU, 1981 Mitral valve prolapse in Klinefelter syndrome. Lancet 2: 8260-8261.

120. Fricke GR, Mattern HJ, Schweikert HU, Schwanitz G, 1984 Klinefelter's syndrome and mitral valve prolapse. an echocardiographic study in twenty-two patients. Biomed Pharmacother 38: 88-97.

121. Andersen NH, Bojesen A, Kristensen K, et al, 2008. Left ventricular dysfunction in Klinefelter syndrome is associated to insulin resistance, abdominal adiposity and hypogonadism. Clin Endocrinol 69: 785-791.

122. Pasquali D, Arcopinto M, Renzullo A, et al, 2013 Cardiovascular abnormalities in Klinefelter syndrome.
Int J Cardiol 168: 754-759.

123. Rosenberg MA, Manning WJ, 2012 Diastolic dysfunction and risk of atrial fibrillation: a mechanistic appraisal. Circulation 126: 2353-2362.

124. Jorgensen IN, Skakkebaek A, Andersen NH, et al, 2015 Short QTc Interval in Males with Klinefelter syndrome-Influence of CAG Repeat Length, Body Composition, and Testosterone Replacement Therapy. Pacing Clin Electrophysiol 38: 472-482.

125. Liu T, Shehata M, Li G, Wang X, 2010 Androgens and atrial fibrillation: friends or foes? Int J Cardiol 145: 365-367.

126. Lai J, Zhou D, Xia S, et al, 2009 Reduced testosterone levels in males with lone atrial fibrillation. Clin Cardiol 32: 43-46.

127. Kang BS, Cho DK, Koh WJ, et al, 2012 A case of severe pulmonary thromboembolism in a young male with Klinefelter syndrome. Korean Circ J 42: 562-564.

128. Lapecorella M, Marino R, De Pergola G, Scaraggi FA, Speciale V, De Mitrio V, 2003 Severe venous thromboembolism in a young man with Klinefelter's syndrome and heterozygosis for both G20210A prothrombin and factor V Leiden mutations. Blood Coagul Fibrinolysis 14: 95-98.

129. Okayama S, Uemura S, Saito Y, 2013 Hypertrophic cardiomyopathy and mesenteric venous thrombosis in a patient with Klinefelter syndrome. Int J Cardiol 166: e50-52.

130. Seth A, Rajpal S, Penn RL, 2013 Klinefelter's syndrome and venous thrombosis. Am J Med Sci 346: 164-165.

131. Campbell WA, Newton MS, Price WH, 1980 Hypostatic leg ulceration and Klinefelter's syndrome. J Ment Defic Res 24: 115-117.

132. Walker N, Rodgers A, Birchall N, Norton R, MacMahon S, 2003 Leg ulceration as a long-term complication of deep vein thrombosis. J Vasc Surg 38: 1331-1335.

133. Astrup T, 1956 The biological significance of fibrinolysis. Lancet 271: 565-568.

134. Astrup T, 1958 The haemostatic balance. Thromb Diath Haemorrh 2: 347-357.

135. Bagot CN, Arya R, 2008 Virchow and his triad: a question of attribution. Br J Haematol. 143: 180-190.

136. Ageno W, Becattini C, Brighton T, Selby R, Kamphuisen PW, 2008 Cardiovascular risk factors and venous thromboembolism: a meta-analysis. Circulation 117: 93-102.

137. Tsai AW, Cushman M, Rosamond WD, Heckbert SR, Polak JF, Folsom AR, 2002 Cardiovascular risk factors and venous thromboembolism incidence: the longitudinal investigation of thromboembolism etiology. Arch Intern Med 162: 1182-1189.

138. Caron P, Bennet A, Camare R, Louvet JP, Boneu B, Sie $\mathrm{P}, 1989$ Plasminogen activator inhibitor in plasma is related to testosterone in men. Metabolism 38: 10101015.

139. De Pergola G, De Mitrio V, Sciaraffia M, et al, 1997 
Lower androgenicity is associated with higher plasma levels of prothrombotic factors irrespective of age, obesity, body fat distribution, and related metabolic parameters in men. Metabolism 46: 1287-1293.

140. Zollner TM, Veraart JC, Wolter M, et al, 1997 Leg ulcers in Klinefelter's syndrome--further evidence for an involvement of plasminogen activator inhibitor-1. Br J Dermatol 136: 341-344.

141. Lijnen HR, 2009 Role of fibrinolysis in obesity and thrombosis. Thromb Res 123: Suppl 4: S46-49.

142. Grainge MJ, West J, Card TR, 2010 Venous thromboembolism during active disease and remission in inflammatory bowel disease: a cohort study. Lancet 375: 657-663.

143. Di Minno MN, Tufano A, Ageno W, Prandoni P, Di Minno G, 2012 Identifying high-risk individuals for cardiovascular disease: similarities between venous and arterial thrombosis in perspective. A 2011 update. Intern Emerg Med 7: 9-13.

144. Oral Contraceptives in the Nineties: Metabolic Aspects - Facts and Fiction. In: Skouby SO, Jespersen J (eds) American Journal of Obstetrics and Gynecology 163: Suppl 2: 273-446.

145. Oral Contraceptives and Cardiovascular Disease. From Myth to Realities. In: Helmerhorst FM, Kluft C, Creatsas G, Jespersen J, Skouby SO, Bloemenkamp K (eds). Gynecological Endocrinology 10: Suppl 2: 1-186.

146. Agledahl I, Brodin E, Svartberg J, Hansen JB, 2009 Plasma free tissue factor pathway inhibitor (TFPI) levels and TF-induced thrombin generation ex vivo in men with low testosterone levels. Thromb Haemost 101: 471-477.

147. Araujo AB, Kupelian V, Page ST, Handelsman DJ, Bremner WJ, McKinlay JB, 2007 Sex steroids and all-cause and cause-specific mortality in men. Arch Intern Med 167: 1252-1260.

148. Glueck CJ, Wang P, 2014 Testosterone therapy, thrombosis, thrombophilia, cardiovascular events. Metabolism 63: 989-994.

149. Basaria S, Coviello AD, Travison TG, et al, 2010 Adverse events associated with testosterone administration. N Engl J Med 363: 109-122.

150. Finkle WD, Greenland S, Ridgeway GK, et al, 2014 Increased risk of non-fatal myocardial infarction following testosterone therapy prescription in men. PLoS One 9: e85805.

151. Vigen R, O’Donnell CI, Baron AE, et al, 2013 Association of testosterone therapy with mortality, myocardial infarction, and stroke in men with low testosterone levels. JAMA 310: 1829-1836.

152. Xu L, Freeman G, Cowling BJ, Schooling CM, 2013 Testosterone therapy and cardiovascular events among men: a systematic review and meta-analysis of placebocontrolled randomized trials. BMC Med 11: 108.

153. Kappert K, Bohm M, Schmieder R, et al, 2012 Impact of sex on cardiovascular outcome in patients at high cardiovascular risk: analysis of the Telmisartan Randomized Assessment Study in ACE-Intolerant Subjects With Cardiovascular Disease (TRANSCEND) and the Ongoing Telmisartan Alone and in Combination With Ramipril Global End Point Trial (ONTARGET). Circulation 126: 934-941.

154. Higgins EJ, Tidman MJ, Savidge GF, Beard J, MacDonald DM, 1989 Platelet hyperaggregability in two patients with Klinefelter's syndrome complicated by leg ulcers. Br J Dermatol 120: 322.

155. Norris PG, Rivers JK, Machin S, Dowd PM, Griffiths WA, 1987 Platelet hyperaggregability in a patient with Klinefelter's syndrome and leg ulcers. Br J Dermatol 117: 107-109.

156. Ferroni P, Basili S, Falco A, Davi G, 2004 Platelet activation in type 2 diabetes mellitus. J Thromb Haemost 2: 1282-1291.

157. Campelo AE, Cutini PH, Massheimer VL, 2012 Testosterone modulates platelet aggregation and endothelial cell growth through nitric oxide pathway. J Endocrinol 213: 77-87.

158. Ajayi AA, Mathur R, Halushka PV, 1995 Testosterone increases human platelet thromboxane A2 receptor density and aggregation responses. Circulation 91: 2742-2747.

159. Khosla S, Melton LJ, Riggs BL, 2011 The unitary model for estrogen deficiency and the pathogenesis of osteoporosis: is a revision needed? J Bone Miner Res 26: 441-451.

160. Fink HA, Ewing SK, Ensrud KE, et al, 2006. Association of testosterone and estradiol deficiency with osteoporosis and rapid bone loss in older men. J Clin Endocrinol Metab 91: 3908-3915.

161. Sinnesael M, Claessens F, Boonen S, Vanderschueren D. Novel insights in the regulation and mechanism of androgen action on bone. Curr Opin Endocrinol Diabetes Obes 20: 240-244.

162. Mellstrom D, Johnell O, Ljunggren O, et al, 2006 Free testosterone is an independent predictor of BMD and prevalent fractures in elderly men: MrOS Sweden. J Bone Miner Res 21: 529-535.

163. Shanbhogue VV, Hansen S, Jorgensen NR, Brixen K, Gravholt CH, 2014 Bone geometry, volumetric density, microarchitecture, and estimated bone strength assessed by HR-pQCT in Klinefelter syndrome. J Bone Miner Res 29: 2474-2482.

164. Breuil V, Euller-Ziegler L, 2001 Gonadal dysgenesis and bone metabolism. Joint Bone Spine 68: 26-33.

165. Bojesen A, Birkebaek N, Kristensen K, et al, 2011 Bone mineral density in Klinefelter syndrome is reduced and primarily determined by muscle strength and resorptive markers, but not directly by testosterone. Osteoporos Int 22: 1441-1450.

166. Ferlin A, Selice R, Di Mambro A, et al, 2015 Role of vitamin D levels and vitamin D supplementation 
on bone mineral density in Klinefelter syndrome. Osteoporos Int 26: 2193-2202.

167. Ferlin A, Schipilliti M, Vinanzi C, et al, 2011 Bone mass in subjects with Klinefelter syndrome: role of testosterone levels and androgen receptor gene CAG polymorphism. J Clin Endocrinol Metab 96: E739-745.

168. Seo JT, Lee JS, Oh TH, Joo KJ, 2007 The clinical significance of bone mineral density and testosterone levels in Korean men with non-mosaic Klinefelter's syndrome. BJU Int 99: 141-146.

169. Overvad S, Bay K, Bojesen A, Gravholt CH, 2014 Low INSL3 in Klinefelter syndrome is related to osteocalcin, testosterone treatment and body composition, as well as measures of the hypothalamic-pituitary-gonadal axis. Andrology 2: 421-427.

170. van den Bergh JP, Hermus AR, Spruyt AI, Sweep CG, Corstens FH, Smals AG, 2001 Bone mineral density and quantitative ultrasound parameters in patients with Klinefelter's syndrome after long-term testosterone substitution. Osteoporos Int 12: 55-62.

171. Kubler A, Schulz G, Cordes U, Beyer J, Krause U, 1992 The influence of testosterone substitution on bone mineral density in patients with Klinefelter's syndrome. Exp Clin Endocrinol 100: 129-132.

172. Friedman A, Waksman Y, 1997 Sex hormones and autoimmunity. Isr J Med Sci 33: 254-257.

173. Al-Arfaj HF, 2010 Klinefelter's syndrome and rheumatoid arthritis: report of a case and review of the literature. Int J Rheum Dis 13: 86-88.

174. Rovensky J, Imrich R, Lazurova I, Payer J, 2010 Rheumatic diseases and Klinefelter's syndrome. Ann N Y Acad Sci 1193:1-9.

175. Scofield RH, Bruner GR, Namjou B, et al, 2008 Klinefelter's syndrome $(47, \mathrm{XXY})$ in male systemic lupus erythematosus patients: support for the notion of a gene-dose effect from the X chromosome. Arthritis Rheum 58: 2511-2517.

176. McMurray RW, May W, 2003 Sex hormones and systemic lupus erythematosus: review and meta-analysis. Arthritis Rheum 48: 2100-2110.
177. Sawalha AH, Harley JB, Scofield RH, 2009 Autoimmunity and Klinefelter's syndrome: when men have two X chromosomes. J Autoimmun 33: 31-34.

178. Rullo OJ, Tsao BP, 2013 Recent insights into the genetic basis of systemic lupus erythematosus. Ann Rheum Dis 72: Suppl 2: 56-61.

179. Costenbader KH, Feskanich D, Stampfer MJ, Karlson EW, 2007 Reproductive and menopausal factors and risk of systemic lupus erythematosus in women. Arthritis Rheum 56: 1251-1262.

180. Bizzarro A, Valentini G, Di Martino G, DaPonte A, De Bellis A, Iacono G, 1987 Influence of testosterone therapy on clinical and immunological features of autoimmune diseases associated with Klinefelter's syndrome. J Clin Endocrinol Metab 64: 32-36.

181. Jimenez-Balderas FJ, Tapia-Serrano R, Fonseca ME, et al, 2001 High frequency of association of rheumatic/ autoimmune diseases and untreated male hypogonadism with severe testicular dysfunction. Arthritis Res 3: 362-367.

182. Kocar IH, Yesilova Z, Ozata M, Turan M, Sengul A, Ozdemir I, 2000 The effect of testosterone replacement treatment on immunological features of patients with Klinefelter's syndrome. Clin Exp Immunol 12: 448-452.

183. Bjorn AM, Bojesen A, Gravholt CH, Laurberg P, 2009 Hypothyroidism secondary to hypothalamic-pituitary dysfunction may be part of the phenotype in Klinefelter syndrome: a case-control study. J Clin Endocrinol Metab 94: 2478-2481.

184. El-Mansoury M, Bryman I, Berntorp K, Hanson C, Wilhelmsen L, Landin-Wilhelmsen K, 2005. Hypothyroidism is common in Turner syndrome: results of a five-year follow-up. J Clin Endocrinol Metab 90: 2131-2135.

185. Viuff MH, Stochholm K, Uldbjerg N, Nielsen BB, Danish Fetal Medicine Study Group, Gravholt CH, 2015 Only a minority of sex chromosome abnormalities are detected by a national prenatal screening program for Down syndrome. Hum Reprod 30: 2419-2426. 